\title{
Semantics of Dialect Verbs with Negative Manifestation of Interpersonal Relationships: Cognitive Aspect
}

\author{
Oksana Peresada* \\ Irkutsk State University, 664003, Karla Marxa av., 1, Irkutsk, Russia
}

\begin{abstract}
The article analyzes the semantics of dialect verbs derivatives with the aim of studying pragmatic aspects of linguistic meaning. Cognitive models of characterizing names of actions associated with interpersonal conflict relations are defined. The cognitive models of functional and characterizing the names have been compared, and the reasons for their differences have been determined. It is established that characterizing verbs of the investigated group can have mono- and poly-propositional structures. It was determined that one of the verb propositions may reflect the objective properties of the named action, the other is the result of evaluating these properties. The evaluation is contained in derivative verbs formed from evaluative, expressive nouns or arises in the process of word-formation on the basis of metaphor. In the process of metaphor creation, the properties of different objects can be compared in the likeness. Propositions can be complicated by a fictitious modality that identifies unrelated actions of an object. In the structure of the propositions of certain verbs, various kinds of causal connection are observed. The presence of metaphorical names is explained by the group's anthropocentrism and special discourse. It turned out that it is important not only to describe the situation and evaluate it, but also to influence the listener.
\end{abstract}

\section{Introduction}

In-depth study of the word-formative semantics of the word led the researchers to the desire to present cognitive processes behind the formation of the derived word. At the present stage, word formation as a whole "acts as a process in which there is an objectification of meanings hidden at other linguistic levels and a representation in the form of hidden meanings of those that appear explicitly at other levels of language" [1].

The method of propositional analysis is aimed at establishing the types of motivational relations between the producer and the derivative, the disclosure of implicit meanings, and their objectification. Research in this perspective allows us to represent the relations of the producer and the derivative in dynamics, which corresponds to the functional principle of the study of linguistic units.

Word formation expresses relationships similar to those that make up the semantics of syntax. As you know, the derived word is formed as a result of the curtailing of the syntactic structure: the runner is the one who runs. Given this similarity, we used the same terminology to study the sentence of the derived word, which is also used in the study of the proposition of the sentence. The main abbreviations used by us in the propositional analysis are $\mathrm{P}-\mathrm{a}$ predicate of the proposition, $\mathrm{S}$ - a subject of the proposition, $\mathrm{O}$ - an object of the proposition, Instr - instrumentalist of the proposition of the derived word, which is also used in the study of the proposition of the sentence.

The units chosen for analysis are verbs formed from nouns, extracted from the dictionary of "Russian dialects of the Baikal region" and "Irkutsk regional dictionary".

The nature of propositional structures largely determines the type of motivation that connects the producing and the derived word and reveals the semantic distance between them.

The study showed that the most common type of motivation for forming verbal verbs is conceptual direct motivation. For example, kapkanit' «lovit' pushnogo zverya kapkanom» $\leftarrow$ kapkan «prisposobleniye dlya lovli zverey».

A derivative verb kapkanit' is the result of a convolution of one proposition (it has a monopropositive structure):

kapkanit' - Nekto (S) lovit (P) pushnogo zverya $(\mathrm{O})$ kapkanom (Instr);

belochit' - Nekto (S) okhotitsya $(\mathrm{P})$ na belku $(\mathrm{O})$.

It turned out that the relationship of direct motivation is characteristic for the formation of verbs that reflect the situation of purposeful activity. They dominate the class of functional names, where, as a rule, the situation of physical impact on the object is presented. For example, in the thematic groups "Fishing activities", "Agricultural activities", "Household".

In the class of characteristic titles, the majority of thematic groups are anthropocentric oriented since one of the components of the meaning of the verbs is "man". As

Corresponding author: art-oksana@yandex.ru 
it turned out, when forming the verbs of these groups, indirect motivations predominate.

A special difficulty is the establishment of propositions of verbs that arose on the basis of metaphor.

1. With metaphorization, the speaker for the designation of an object, property, process, state, etc., which does not yet have a name, turns to searches in something similar, but already named in the language of the entity [2].

At the heart of most of the metaphors, there are connotations, "inessential but stable signs of the concept expressed by it, which embody the assessment of the relevant subject or fact of reality accepted in a given language collective" [3]. "The connotation is the connecting link between two different units of language and the relation, in which it puts these two units as the ratio of assimilation" [3].

L.N. Jordanian and I.A. Melchuk introduced the component "as if" to describe the likeness, justifying his introduction as follows: "This component defines the" inner form "of the meaning, its figurative structure, its semantic etymology, so to speak" [4]. The relationship of false identity, reduced to the form of "as if". V.N.Telia calls the Fictitious Modus [5]. "The assumption of similarity, which we consider fundamental for metaphorization ..., is a metaphoric mode that can be given the status of the Kantian fictitious principle, the meaning of which is expressed in the form of" as if "" [2].

At word-formation from the noun, the Fictitious modus puts the sign of false identity between two directly unrelated properties of objects or two directly unrelated properties of one object on the basis of their similarity [6].

2. This statement is based on the interaction theory of metaphor, which is set forth in the works of Richards (1950), Black (1962) [7]. Metaphor, according to the authors, is a semantic mechanism in which four components participate, only partially represented in its surface structure: the main and auxiliary subjects of the metaphor and some properties of each of them [8]. For example: zmeya "presmykayushcheyesya $s$ dlinnym izvivayushchimsya telom, bez nog, obychno yadovitoye» $\rightarrow$ zmeyevik «trubka, obychno izognutaya spiral'yu».

Thus, the logical formula of metaphorical motivation fixes the combination of two propositions [9]. Z.I. Rezanova gives two variants of the record: ( $\mathrm{X}$ has the attribute [A) belongs to $\mathrm{Y}]$ and ( $\mathrm{X}$ is $[\mathrm{Y}$ ) on the basis of A]. In these schemes "different aspects of complex interaction are fixed - the aspect of identification of two objects (the second formula), or the aspect of comparison (the first) [9]. This understanding reflects two traditions in the interpretation of the metaphor: they distinguish "metaphors that are built on the basis of a direct similarity between two objects, and metaphors based on the general relationship experienced (sometimes by pure chance or a number of reasons) by us to both objects" 10].

With metaphorical transfer, there can be a process of shifting the emphasis from identification to comparison, and vice versa. We will describe the comparison process with the help of the operator "similar", the identification - "as if".

Establishing the structure of the proposition of verb derivatives, it is important to pay attention not only to the denotative component of the value that describes the fact of reality but also to the evaluative, expressing the evaluation of this fact to the speaker. The value component of the value can provide information that allows a conclusion about the value system of rural residents.

Opinions among linguists about the ratio of rational (or intellectual) and emotional (associated with feelings) in the assessment diverge. These are two different aspects of the subject's relationship to the object, the first is his opinion, the second is feelings. According to the linguists VN. Telia, V.I. Shakhovsky, N.A. Lukyanova, the evaluation procedure is a rational operation, although the basis of the assessment is an emotion: interest is something that worries us. However, in the assessment itself is expressed not an emotion, but an operation of "scaling" the norms of being [2]. This evaluation directly describes the feelings (joyful - sad, pleasant - unpleasant, etc.). "Evaluation, as it were," absorbs "the corresponding emotion, and the parameters of emotion and evaluation coincide " pleasant "-" good "," unpleasant "-" bad "" [11]. In a separate class of Telia, V.I. a feeling that is felt - an attitude experienced not under the influence of the designated, but as to how it is presented as a stimulus and calls it an emotional evaluation [2]. Emotional evaluation in comparison with the list of illocution verbs Searle JR [12] is included in the "approval/disapproval" range. Emotional evaluation is not "amalgamated" with rational, but "layered" on it, referring not to the properly designated, but to the motivational basis of the expression [2]. In the process of moral activity, the subject performs an appraisal categorization of human actions. The similarity of any actions committed by a person with patterns of moral behaviour is taken into account, their conformity or inconsistency of normative activity is established, a conclusion is made about a positive or negative appraisable act, a subjective attitude is expressed [13]. During word-formation from the noun, the Fictitious modus puts the sign of false identity between two directly unrelated properties of objects or two directly unrelated properties of one object on the basis of their similarity [6].

We describe the estimated component of the meaning of one of the verbs being analyzed: zubit'sya «ogryzat'sya, otvechat' yazvitel'no, derzko» (such speech is unpleasant to listen to, it is unethical), so zubit'sya Badly. Procedurally emotive interpretation of information will enter cognitive "test" of the operator: Test disapproval.

One of the centres in the classification of the verbal lexicon is the lexico-semantic group of related verbs. In this group, we can distinguish the subgroup "interpersonal relations". M.V. Frolova proposes to consider interpersonal relations as "subjectively experienced interrelations between people, objectively manifesting themselves in the nature and ways of mutual influences 
rendered by people on each other in the process of joint activity and communication" [14].

S.V. Vaganova distinguishes between verbs of interpersonal relations and the verbs of emotionally appraising relation (trust, envy), verbs of external manifestation of relation (caress, scoff), contact verbs (get acquainted, get along, quarrel) [15]. In research works such verbs are called verbs of complex action (E.V. Kuznetsov, E. N. Remchukova), verbs with complicated meaning (N. Yu. Shvedova), verbs with complex semantics (Yu. S. Maslov), because the way the manifestations of relationships can be different: through speech, facial expression, action, gesture, behavior. In addition, in each subgroup it is possible to select this emotional-evaluative relation ("positive", "neutral", "negative") and this "intensity of emotions" (intense / nonintensive).

Let us consider features of the semantics of dialect verbs with a negative display of interpersonal relations. The group "Names of actions related to emotionalevaluative attitude" is represented by the following verbs: zubit'sya «to snap back, respond sarcastically, defiantly», kastorit" "scold», kurazhit'sya «be capricious», navetnichat' "slander, falsely accuse», raskuporosit'sya "get angry, get nervous ", shalokhvostit" "to gossip», egoiznichat" «show selfishness, mischief, capricious».

The group "Naming actions related to the interruption of contact" is represented by the following verbs: naproskuchit' «bored», obesstuzhit'sya «offended, angry», otparit'sya «separate from someone, disunite».

The group "Naming actions related to external negative manifestation of relationships" is represented by the following verbs: bombit' "fight», buruzdit' «scratch», zhalit" "to lash, to whip, to beat», kolotushnichat" "to bully, to fight», myasnichat" "beat up», oteterit' "to strike», rogatit'sya «to bully», telesnut' «hit hard».

Monopropositive structures:

1) Kolotushnichat' - Kolotushnik (S) performs an action characteristic of him. Someone thinks that this is bad. This causes disapproval (Expr.).

Shalokhvostit' - Shalokhvost (S) performs an action characteristic of him. Someone thinks that this is bad. This causes disapproval (Expr.).

2) Kurazhit'sya - Someone shows kurazh $(P)$ before someone. Someone thinks that this is bad.

Egoiznichat' - Someone shows egoizm $(P)$ before someone. Someone thinks that this is bad.

Navetnichat' - Someone erects navet $(P)$ on someone. Someone thinks that this is bad.

Prikhotnichat' - Someone expresses prikhoti $(P)$ to someone. Someone thinks that this is bad.

Naproskuchit' - Somebody causes skuku (P) from someone. Someone thinks that this is bad.

3) Omnapumbcя - Someone lost pary $(O)$.

Telesnut' - Someone hit hard on someone's telu $(O)$. Someone thinks that this is bad. This causes disapproval (Expr.).

The polypropositivity of the estimated non-verbal verbs and metaphorical names has a different nature. Therefore, in order to establish patterns in further analysis, all verbs with a second evaluation proposition will be conditionally considered in a series of monopropositive structures.

The surface structure of some monopropositive verbs is the subject of the proposition. The type of proposition is due to the one-dimensional semantics of the producer, who has a high predictive power. Evaluation of the action of the Person on the basis of "more than normal" is inherited from the producing unit, which calls the attribute, which in itself is no longer the norm: shalokhvost - gossip, kolotushnik - fighter, bully.

The nominal part of the predicate is also in the surface structure of monopropositive derivatives of verbs. This is an abstract noun (egoizm, prikhoti, skuka). As is known, abstract nouns denote qualities or attributes abstracted from the object and presented as substances. Consequently, they are significative (non-referential) words and lack "denotative orientation", which actualizes the different meaning of the language unit, depending on the situation [16].

In the structures of verbs "telesnut"' and "otparit'sya" an object argument is explicated. The verb "otparit'sya" is formed from a noun with a quantitative meaning. The prefix ot- specifies the meaning of the predicate "otdelit'sya". The suffix -nu in the verb "telesnut" has not only the meaning of a single instantaneous action but also embodies the expressive component "strongly".

Predicting semantics of motivators determines the minimal phraseological character of verbs with a monopropositive structure. Verbs refer to names with an evaluation predicate "good/bad". However, in semantics there is no seme of intensity, therefore the names are not expressive.

The other verbs analyzed have polypropositive structures.

Polypropositional structures:

1) Zubit'sya - Someone utters words. Words are sharp. The $Z u b$ is sharp. Words are like zubam. Someone thinks that this is bad.

Obesstuzhit'sya - Someone is experiencing resentment to someone. The Stuzha is cold. Resentment is like stuzhe.

Buruzdit' - Somebody makes scratches to someone. Borozda is a strip. Scratches are like borozdam. Someone thinks that this is bad.

Zhalit' - Someone is flogging someone with something (talinoy). Zhalo is sharp. Talina is similar to zhalu. Someone thinks that this is bad. This causes disapproval (Expr.).

2) Kuchit'sya - Somebody beggars someone. The request is a rapprochement as if somebody creates kuchu. A heap is a rapprochement. The request is similar $v$ kuchu.

Spulit'- Someone says quickly as if Pulya flies quickly, sharply. The conversation is like the flight puli. Someone thinks that this is bad.

Kastorit' - Someone scolds someone. Someone is unpleasant as if someone gives kastorku to someone. Someone is unpleasant. Kastorka is unpleasant. Swearing is like drinking kastorki. Someone thinks that this is bad. 
3) Myasnichat' - Somebody hits someone so much that (caus) Myaso has appeared. Someone thinks that This is bad. This causes disapproval (Expr.).

Zakhaylat' - Someone opens khaylo to (caus) someone started to swear. Someone thinks that this is bad. This causes disapproval (Expr.).

Raskuporosit'sya - Someone is angry, therefore (caus) someone blushes as if Kuporos covers the metal, so (caus) Metal blushes. Someone is like a metal.

Rogatit'sya - Somebody began to bully up as though the Bull was bullish, therefore (caus) The Bull exposes roga. Tugging someone like tearing bull's rogov. Someone thinks that this is bad.

Bombit' - Somebody beats someone so much that (caus) Noise is heard as if Bomba exploded. The noise of the fight is like bomby explosion. Someone thinks that this is bad. This causes disapproval (Expr.).

These are metaphorical derivatives: zhalit', buruzdit', zubit'sya, obesstuzhit'sya. In the process of metaphorization, the properties of two different objects are compared on the basis of the similarity of the impression produced or the similarity of the appearance.

The phraseological "tochit' zuby" (to be angry, to try to do harm) probably influenced the meaning of the verb zubit'sya. The verb "zhalit" represents a special case. The meaning of the verb is formed either as a result of derivational derivation based on the value of the motivator zhalo, or as a result of semantic derivation based on the national meaning of the verb zhalit' "wound stings, bite." Perhaps both of these processes were involved in the formation of the meaning of the dialect verb. It should be noted that the verb obesstuzhit'sya has a paradoxical superficial structure. The prefix -obez/c has the meaning "deprive something, free it from something". Therefore, if one believes in the external form of the word "obesstuzhit'sya", it must have the meaning "to lose stuzhi" and to call the situation of their rapprochement not the situation of disunion of people. The discrepancy between the surface structure of a word and its meaning enhances phraseology. The verbs kastorit', spulit', kuchit'sya are polypropositional structures are complicated by a fictitious modus (as it were). The fictitious modality puts the sign of identity between two directly unrelated actions of one object or different. Verbs zakhaylat' and myasnichat' have a polypropositional structure with a causal connection.

Structures of verbs bombit', rogatit'sya, raskuporosit'sya even more complex. Polypropositive structures with a causal connection are complicated by a fictitious modality. These verbs are highly idiomatic. The semantics of the verb rogatit'sya are formed on the basis of a two-step associative connection. At the first stage, two modes of action are compared: animal and human, in the second stage the mode of action of the animal is concretized.

The structure of the verb raskuporosit'sya is more complex. It consists of five propositions, 1 and 2, 3 and 4 are related to each other by causal causation. The propositions of the investigation are compared using the Fictitious Modus. In the surface structure, the components of the propositions of the cause are realized (the predicate of the first and the subject of the third proposition). Thus, we see in the verbs raskuporosit'sya, rogatit'sya different kinds of causal connection between the propositions of propositions: the cause-effect, the target. In the syntax, such relations between predicative units as part of compound sentences are referred to as dismembered. Communication in dissected sentences is unpredictable.

In examples, myasnichat' and bombit' another link between propositions. The main proposition is characterized by the presence of a correlative word or a stable combination of "so", "to such a degree", i.e. words with a qualitative - qualitative or quantitative - meaning. In the syntax, such sentences with a correlation (pronominal-relative) connection are considered undivided. In the examples analyzed, the correlative word is associated with the whole proposition of the second proposition (the subordinate part), but this connection has an indirect character and is based on elements of meaning that do not receive verbal expression but are inherent in the construction as a whole. We can conclude that these names are highly phraseological based on the types of connection between propositional propositions of verbs. Their idiomaticity is determined not only by the incomplete severity of the components of the DM, the polypropositional structure, but also by the indirect, indirect connection between the propositions' judgments.

In the group, the verb oteterit' with a paradoxical internal form (the term of T.V. Matveeva [17]) was found. It is impossible to establish the semantic connection between the producer and the derivative in this case. The verb is formed from the noun by some "random signs".

Teterya 1. A large bird from the order of chickens. 2. It is disapproving of a person (deaf, sluggish, sleepy). Context: 1. And she wakes me up with oteterit on the head in the morning. 2. He oteteril him firmly on the back - and yours is gone.

T.V. Matveeva writes, "In the event of a divergence of the derivative and the production of semantics, the relationship between them is determined by the emotional-evaluative components of the latter, often potential" [17].

External manifestations of emotions and feelings of a person are expressive reactions, in particular, expressive vocabulary. The person in irritation and anger replaces the neutral words "udaril", "stuknul" on the expressive type "oteteril", picking up unusual motivators for the formation of words. T.V. Matveeva believes that the originally motivated link between the producer and the derivative still existed, but, having an associative character, easily lost [17].

That is, we cannot restore the proposition of such words, but the propositional attitude (the attitude of the subject of evaluation to the object of evaluation) is preserved.

Vocabulary, characterizing the state of anger, rage, and also the person in this state, has the highest expressive colouration, and with a clearly pronounced negative connotation. All the structures of the above verbs with sema "swear", "fight" includes a valuation mode reflecting the nominee's opinion on the named 
action "This is bad." Expressive words (haylo) can act as motivators, as well as words whose semantics seem to be unrelated to the semantics of the derivatives of this group: castorka, cuporos. "Ordinary" words or words with a lesser degree of colouring seem to a person insufficiently capacious to express his emotional state. The estimated component of the meaning of most verbs of this group includes this intensity, or intensity and imagery, which allows considering these names expressive.

Thus, the main means for creating expressively derivatives of verbs are the selection of expressive motivators, as well as the use of metaphorical motivation in the nomination process. In addition, we note that most verbs of the thematic groups under analysis have a complex formal structure. Their ways of reflecting pref.suf., suf.-post., pref.-suf.-post. Perhaps using more complex ways of education is also one means of creating expression.

In the course of the study, it became clear that the nomination technique changes depending on the speaker's goal. Functional names are represented, as a rule, by monopropositive structures, which is connected with the repeatability, monotony of the situation. "The lack (small amount) of metaphors signals a discourse in which - people do not need to speak on abstract topics; there is no need to verbalize the surrounding world "[18]. Situations represented by names that characterize the relationships of people have a more complex scenario than situations of purposeful activity (functional verbs). Because of the complexity of the situation, one cannot do without the formation of one proposition; there is a chain of interconnected propositions complicated by various modus senses [19]. Verbs are dominated by metaphors with a communicative centre of bias toward identification, no comparison. This can be explained by the following: in the dialectal wordformation for the nominator, not only is the sign of comparison important, but also its manifestation, as well as the evaluation of this manifestation. At the heart of metaphoric motivation, as already mentioned, are connotations. According to O.A. Burukina, the connotation is inextricably linked with emotions, which are an effective instrument of influence. Thus, we can talk about the suggestive function of connotation, which also has a cognitive nature [20]. The speaker of dialects is important not only to describe the situation and give his own assessment of what is displayed but also to influence the listener.

\section{References}

1. Z.A. Haritonchik, The structure of the proposition and its reflection in word-formation processes, Derivation in speech activity (linguistic units), 4749, (1991)

2. V.N. Teliya, Russian phraseology. Semantic, pragmatic and linguocultural aspects (SHk. «YAzyki rus. kul'tury», Moscow, 1996)

3. Yu. D. Apresyan, Connotations as part of the pragmatics of speech (lexicographical aspect),
Russian: Probl. gram. semantics and evaluation factors in the language, 45-64, (1992)

4. L.N. Iordanskaya, I.A. Melchuk, Wiener Slawistischer Flmanach Bd.6, 191-210, (1980)

5. V.N. Telia, Metaphorization and its role in creating a linguistic picture of the world, The role of the human factor in language. Language mechanisms of expressiveness, 36-66, (1991)

6. E.A. Oglezneva, Nominative field of the derived noun of a specific semantics in the Russian dialects of the Amur River (Tomsk, 1996)

7. The theory of metaphor (Progress, Moscow, 1990)

8. N.D. Arutyunova, Metaphor and Discourse, Teoriya metafory, 5-32, (1990)

9. Z.I. Rezanova, Functional Aspect of Word Formation (Izd-vo Tom. Un-ta, Tomsk, 1996)\

10. A. Richards, Philosophy of Rhetoric, Theory of Metaphor, 44-67, (1990)

11. N.A. Lukyanova, Expressive vocabulary of spoken use (the problem of semantics) (Nauka Publ., Novosibirsk, 1986)

12. J. R. Searle, NZL. The theory of speech acts $\mathbf{1 7}$, (1986)

13. A.J. Dossanova, J.B. Nurmahanova, Questions of Cognitive Linguistics 1 (042), 50-54, (2015)

14. M.V. Frolova, Functioning of verbs of interpersonal and social relations in the works of Russian literature of the 1920 XX century (based on the texts of AP Platonov and MA Bulgakov) (Volgograd, 2008)

15. S.B. Vaganova, Journal collection of scientific works of krasec section «The humanities» 1 (17), (2011)

16. Linguistic encyclopedic dictionary (Sov. Ehnciklopediya, Moscow, 1990)

17. T.V. Matveeva, To the relation of the semantics of the derivative of an expressive verb with the semantics of its components, Questions of word and form formation in Indo-European languages, (1991)

18. F.A. Eloeva, E.V. Perehval'skaya, E. Sauswerda, Questions of linguistics 1, 78-99, (2014)

19. O.V. Artem'eva, Ofsubstantive verbs in the dialects of the Baikal region and the Irkutsk region: the cognitive aspect (Tomsk, 2000)

20. O.A. Burukina, Researches of connotation from the viewpoint of cognitive linguistics, Questions of Cognitive Linguistics 3 (024), 35-40, (2010) 